\title{
Commentary: A Breath of Fresh Air on the Mesenchyme: Impact of Impaired Mesenchymal Development on the Pathogenesis of Bronchopulmonary Dysplasia
}

\author{
Eric S. White* \\ Division of Pulmonary and Critical Care Medicine, Department of Internal Medicine, University of Michigan Medical School, \\ Ann Arbor, MI, USA
}

Keywords: bronchopulmonary dysplasia, mesenchymal cells, fibrosis, lung diseases, embryonic development

OPEN ACCESS

Edited by:

Anne Hilgendorff, Helmholtz Zentrum München,

Germany

Reviewed by: Cristina Maria Alvira

Stanford University School

of Medicine, USA

Melanie Königshoff, Helmholtz Zentrum München,

Germany

${ }^{*}$ Correspondence:

Eric S. White

docew@umich.edu

Specialty section:

This article was submitted to

Pulmonary Medicine,

a section of the journal

Frontiers in Medicine

Received: 26 August 2015

Accepted: 24 March 2016

Published: 31 March 2016

Citation:

White ES (2016) Commentary: A

Breath of Fresh Air on the

Mesenchyme: Impact of Impaired

Mesenchymal Development on the

Pathogenesis of Bronchopulmonary

Dysplasia.

Front. Med. 3:13

doi: 10.3389/fmed.2016.00013

\section{A commentary on}

A breath of fresh air on the mesenchyme: impact of impaired mesenchymal development on the pathogenesis of bronchopulmonary dysplasia

by Chao C-M, El Agha E, Tiozzo C, Minoo P, Bellusci S. Front Med (2015) 2:27. doi: 10.3389/ fmed.2015.00027

Bronchopulmonary dysplasia (BPD) is a chronic lung disease of prematurity that is only now beginning to be understood at the molecular level. The review by Chao et al. (1) elegantly takes us through mouse and human lung development to identify possible mediators of the abnormal mesenchymal response characteristic of the disease. However, it quickly becomes clear that many aspects of BPD development seem to mimic chronic lung disease in adults. For example, secondary septa formation is a critical step in alveologenesis, with alveolar simplification in BPD thought to result from disordered septation. In the emphysematous adult lung, enlarged airspaces reminiscent of alveolar simplification are also seen; importantly, evidence suggests that many mediators thought to be important in BPD development are also important in COPD pathogenesis, such as wingless and int (Wnt) (2,3), fibroblast growth factor (FGF) $(4,5)$, and sonic hedgehog (Shh) (6). Similarly, exuberant collagen and elastin deposition during alveologenesis bears remarkable similarity to the deposition of extracellular matrix proteins during adult lung fibrogenesis (7), although it is unclear whether the pattern and relative quantities of proteins are also similar. These observations, plus others, suggest a potential stereotypic lung injury response resulting in disrepair in adult lung and abnormal development in the neonate.

Despite the differences in etiology, both BPD and chronic adult lung injury are characterized by elevated expression and activity of transforming growth factor (TGF)- $\beta$, perhaps the most wellknown profibrotic cytokine. Implicated in epithelial-mesenchymal transition (EMT) (8), myofibroblast differentiation (9), and epithelial apoptosis (10), TGF- $\beta$ overexpression may be pathogenic for BPD, emphasizing the critical need for TGF- $\beta$ regulation during fetal lung development (11). Similarly, in adult lung, TGF- $\beta$ overexpression is maladaptive, resulting in fibrosis that has been likened to recapitulation of developmental programs (12). Understanding how dysregulated TGF- $\beta$ activity perturbs both normal development and postnatal lung repair has yet to be determined, but side-by-side comparisons of the role of mesenchymal cells in lung development and disease will likely shed further insight. 
An intriguing aspect of the review by Chao et al. is the supportive role of the lipofibroblasts (LIFs), the interstitial fibroblasts identified in rodent lungs containing cytoplasmic lipid droplets (13) thought to be important in alveolar epithelial cell surfactant production. Despite one manuscript showing the existence of LIFs in human lung (14), controversy still remains (15) about the existence of this cell in humans. While LIFs seem to contribute to secondary septation in developing rodent lungs through transfer of lipids to Type II alveolar epithelial cells (16), their role in the adult rodent lung (if any) remains unclear. To be certain if LIFs are developmentally important and potentially reparative mesenchymal cells of the lung, identifying them in human lung of any age would be of paramount importance. Similarly, it will be important to determine whether LIFs are truly a separate type of mesenchymal cell or whether they are simply interstitial fibroblasts that uptake lipid droplets for transfer to alveolar epithelium. Currently, there are few known markers of LIFs, such as platelet-derived growth factor receptor (PDGFR)- $\alpha$ and peroxisome proliferator-activated receptor (PPAR)- $\gamma$ (17), but these are not specific for LIFs. More work in this area will obviously be necessary.

Mesenchymal-epithelial crosstalk, as described above for LIFs and type II alveolar epithelial cells, is obviously important for lung development, as nicely illustrated by Chao and colleagues (1). However, less is known about the contribution of the endothelium, and more specifically mesenchymal-endothelial interactions, in the development of chronic lung diseases, including BPD. Clearly, the transformation of a double vasculature to a single capillary system in primary alveolar septae is integral to gas exchange in the developing lung, as pointed out by Chao and colleagues. The development of this vasculature occurs through both angiogenesis and vasculogenesis. Along the same line, angiogenesis and vasculogenesis appear to be important in the development of

\section{REFERENCES}

1. Chao CM, El Agha E, Tiozzo C, Minoo P, Bellusci S. A breath of fresh air on the mesenchyme: impact of impaired mesenchymal development on the pathogenesis of bronchopulmonary dysplasia. Front Med (2015) 2:27. doi:10.3389/ fmed.2015.00027

2. Baarsma HA, Spanjer AI, Haitsma G, Engelbertink LH, Meurs H, Jonker MR, et al. Activation of WNT/beta-catenin signaling in pulmonary fibroblasts by TGF-beta(1) is increased in chronic obstructive pulmonary disease. PLoS One (2011) 6:e25450. doi:10.1371/journal.pone.0025450

3. Kneidinger N, Yildirim AO, Callegari J, Takenaka S, Stein MM, Dumitrascu $\mathrm{R}$, et al. Activation of the WNT/beta-catenin pathway attenuates experimental emphysema. Am J Respir Crit Care Med (2011) 183:723-33. doi:10.1164/ rccm.200910-15600C

4. Shi W, Chen F, Cardoso WV. Mechanisms of lung development: contribution to adult lung disease and relevance to chronic obstructive pulmonary disease. Proc Am Thorac Soc (2009) 6:558-63. doi:10.1513/pats.200905-031RM

5. Kranenburg AR, De Boer WI, Van Krieken JH, Mooi WJ, Walters JE, Saxena PR, et al. Enhanced expression of fibroblast growth factors and receptor FGFR-1 during vascular remodeling in chronic obstructive pulmonary disease. Am J Respir Cell Mol Biol (2002) 27:517-25. doi:10.1165/rcmb.4474

6. Kugler MC, Joyner AL, Loomis CA, Munger JS. Sonic hedgehog signaling in the lung. From development to disease. Am J Respir Cell Mol Biol (2015) 52:1-13. doi:10.1165/rcmb.2014-0132TR certain adult chronic lung diseases, such as COPD, asthma, and idiopathic pulmonary fibrosis (IPF) (18-20). Indeed, nintedanib, a tyrosine kinase inhibitor that blocks vascular endothelial growth factor receptor, FGF receptor, and PDGFR, has recently gained approval around the world for treatment of IPF because of its effects on slowing the rate of decline of lung function (21). It is not yet known whether the salutary effect of nintedanib in IPF is related to its inhibitory effects on angiogenesis.

We have certainly learned much about BPD pathogenesis through elegant mouse modeling and human pathologic studies. However, there is still much to learn; murine studies, while informative, cannot take the place of knowledge generated in human samples of disease. Moreover, although mouse lung development occurs in a stereotypic fashion which has been well characterized, it is not proven that human lung development occurs entirely in the same way. Thus, better methods of studying human lung development need to be created and validated, with findings hopefully informing our understanding of chronic adult lung diseases as well.

As alluded to by Chao and colleagues (1), the incidence of BPD and its long-term effects appears to be on the rise as more premature infants survive owing to advances in supportive care. There are no definitive therapies for these patients. Just as research into the lung mesenchyme will surely enlighten our understanding of $\mathrm{BPD}$, researchers of all chronic lung diseases are likely to gain better insights into disease pathogenesis and potentially pave the way for future therapies in numerous diseases. Impaired mesenchymal development and responses - it is not just for BPD.

\section{AUTHOR CONTRIBUTIONS}

The author confirms being the sole contributor of this work and approved it for publication.

7. Kuhn C, Mcdonald JA. The roles of the myofibroblast in idiopathic pulmonary fibrosis. Ultrastructural and immunohistochemical features of sites of active extracellular matrix synthesis. Am J Pathol (1991) 138:1257-65.

8. Kim KK, Kugler MC, Wolters PJ, Robillard L, Galvez MG, Brumwell $\mathrm{AN}$, et al. Alveolar epithelial cell mesenchymal transition develops in vivo during pulmonary fibrosis and is regulated by the extracellular matrix. Proc Natl Acad Sci U S A (2006) 103:13180-5. doi:10.1073/ pnas.0605669103

9. Thannickal VJ, Lee DY, White ES, Cui Z, Larios JM, Chacon R, et al. Myofibroblast differentiation by transforming growth factor-betal is dependent on cell adhesion and integrin signaling via focal adhesion kinase. J Biol Chem (2003) 278:12384-9. doi:10.1074/jbc.M208544200

10. Hagimoto N, Kuwano K, Inoshima I, Yoshimi M, Nakamura N, Fujita M, et al. TGF-beta 1 as an enhancer of Fas-mediated apoptosis of lung epithelial cells. J Immunol (2002) 168:6470-8. doi:10.4049/jimmunol.168.12.6470

11. Zeng X, Gray M, Stahlman MT, Whitsett JA. TGF-betal perturbs vascular development and inhibits epithelial differentiation in fetal lung in vivo. Dev Dyn (2001) 221:289-301. doi:10.1002/dvdy.1140

12. Selman M, Pardo A, Kaminski N. Idiopathic pulmonary fibrosis: aberrant recapitulation of developmental programs? PLoS Med (2008) 5:e62. doi:10.1371/ journal.pmed.0050062

13. Mcgowan SE, Torday JS. The pulmonary lipofibroblast (lipid interstitial cell) and its contributions to alveolar development. Annu Rev Physiol (1997) 59:43-62. doi:10.1146/annurev.physiol.59.1.43 
14. Rehan VK, Sugano S, Wang Y, Santos J, Romero S, Dasgupta C, et al. Evidence for the presence of lipofibroblasts in human lung. Exp Lung Res (2006) 32:379-93. doi:10.1080/01902140600880257

15. Ahlbrecht K, Mcgowan SE. In search of the elusive lipofibroblast in human lungs. Am J Physiol Lung Cell Mol Physiol (2014) 307:L605-8. doi:10.1152/ ajplung.00230.2014

16. Torday J, Hua J, Slavin R. Metabolism and fate of neutral lipids of fetal lung fibroblast origin. Biochim Biophys Acta (1995) 1254:198-206. doi:10.1016/0005-2760(94)00184-Z

17. Rehan VK, Torday JS. The lung alveolar lipofibroblast: an evolutionary strategy against neonatal hyperoxic lung injury. Antioxid Redox Signal (2014) 21:1893-904. doi:10.1089/ars.2013.5793

18. Calabrese C, Bocchino V, Vatrella A, Marzo C, Guarino C, Mascitti S, et al. Evidence of angiogenesis in bronchial biopsies of smokers with and without airway obstruction. Respir Med (2006) 100:1415-22. doi:10.1016/j. rmed.2005.11.009

19. Voelkel NF, Douglas IS, Nicolls M. Angiogenesis in chronic lung disease. Chest (2007) 131:874-9. doi:10.1378/chest.06-2453
20. Keane MP, Arenberg DA, Lynch JP III, Whyte RI, Iannettoni MD, Burdick MD, et al. The CXC chemokines, IL-8 and IP-10, regulate angiogenic activity in idiopathic pulmonary fibrosis. J Immunol (1997) 159:1437-43.

21. Roth GJ, Binder R, Colbatzky F, Dallinger C, Schlenker-Herceg R, Hilberg F, et al. Nintedanib: from discovery to the clinic. J Med Chem (2015) 58:1053-63. doi:10.1021/jm501562a

Conflict of Interest Statement: The author declares that the research was conducted in the absence of any commercial or financial relationships that could be construed as a potential conflict of interest.

Copyright (C) 2016 White. This is an open-access article distributed under the terms of the Creative Commons Attribution License (CC BY). The use, distribution or reproduction in other forums is permitted, provided the original author(s) or licensor are credited and that the original publication in this journal is cited, in accordance with accepted academic practice. No use, distribution or reproduction is permitted which does not comply with these terms. 